\title{
Correction to: Engagement in migrant organizations for immigrant integration: A mixed-method study with Peruvians in Chile
}

\section{Daniela Marzana ${ }^{1,2}$ (D) Sara Martinez Damia ${ }^{1,2}$ (D) Elena Marta ${ }^{1,2}$ (D) Maura Pozzi ${ }^{1,2}$ (D) Maria Loreto Martínez ${ }^{3}$ (D)}

Published online: 1 March 2022

๑) Springer Nature B.V. 2022

\section{Correction to: Journal of International Migration and Integration https://doi.org/10.1007/s12134-021-00928-9}

The original version of the article unfortunately contained an error.

The first and last names of three authors were inadvertently interchanged. The correct authors names and surnames are shown above.

The original article has been corrected.

Publisher's Note Springer Nature remains neutral with regard to jurisdictional claims in published maps and institutional affiliations.

The original article can be found online at https://doi.org/10.1007/s12134-021-00928-9.

Daniela Marzana

daniela.marzana@unicatt.it

Sara Martinez Damia

saramaria.martinezdamia1@unicatt.it

Elena Marta

elena.marta@unicatt.it

Maura Pozzi

maura.pozzi@unicatt.it

Maria Loreto Martínez

mlmartig@uc.cl

1 Psychology Department, Università Cattolica del Sacro Cuore, Largo Gemelli 1, 20123 Milano, Italy

2 CERISVICO Research Centre on Community Development and Organisational Quality of Life, via Trieste 17 , Brescia, Italy

3 Pontificia Universidad Católica de Chile, Santiago, Chile 